\title{
POSSÍVEIS RELAÇÕES ENTRE A VARIABILIDADE INTERANUAL DO GELO MARINHO ANTÁRTICO E A PRECIPITAÇÃO NA AMÉRICA DO SUL
}

\author{
Camila B. Carpenedo ${ }^{1}$; Tércio Ambrizzi ${ }^{1}$; Luis A. L. Aímola² \\ ${ }^{1}$ Departamento de Ciências Atmosféricas - IAG/USP \\ ${ }^{2}$ Instituto Tecnológico Vale - Desenvolvimento Sustentável \\ e-mail: carpenedo@model.iag.usp.br
}

\begin{abstract}
RESUMO
Investigamos as diferenças na circulação atmosférica do Hemisfério Sul em extremos interanuais de retração e expansão de gelo marinho antártico e as possíveis relações com a precipitação na América do Sul. Os resultados mostram que, com a retração de gelo marinho no mar de Weddell e Bellingshausen-Amundsen (mar de Ross), houve uma redução (aumento) de precipitação no Nordeste do Brasil. Na região Sul, houve um aumento associado aos mares de Bellingshausen-Amundsen. Estas relações não foram tão evidentes através das células de circulação meridional, mas através de padrões de teleconexão barotrópico equivalente de latitudes extratropicais.
\end{abstract}

\begin{abstract}
We investigated the differences in atmospheric circulation in the Southern Hemisphere in interannual extreme of retraction and expansion of Antarctic sea-ice and possible relationships with precipitation in South America. The results show that with the decrease of sea-ice in the Weddell and Bellingshausen-Amundsen seas (Ross Sea) there was an decrease (increase) of precipitation in Northeast Brazil. In the South there was an increase associated with the Amundsen-Bellingshausen Seas. These relationships were not as evident through the cells of meridional circulation, but through equivalent barotropic teleconnection patterns in extratropical latitudes.
\end{abstract}

\section{INTRODUÇÃO}

A América do Sul possui uma economia altamente dependente da agricultura. Tanto fatores locais quanto regionais e remotos podem contribuir para as condições meteorológicas e climáticas nas regiões produtoras. Assim, o objetivo deste estudo foi investigar as diferenças na circulação atmosférica do Hemisfério Sul em extremos interanuais de retração e expansão de gelo marinho (GM) antártico e as possíveis relações com a precipitação na América do Sul, com enfoque sobre o Brasil.

\section{MATERIAL E MÉTODO}

Para o período de 1989 a 2007 foram utilizados os campos de superfície até a alta troposfera das reanálises do ERA-Interim (ECMWF Data Server); precipitação do Global Precipitation Climatology Project (GPCP), versão 2.2, e radiação de onda longa emergente (ROLE) da NOAA; extensão de GM do National Snow and Ice Data Center (Universidade do Colorado) para cada setor do Oceano Austral: mar de Weddell (MW, $60^{\circ} \mathrm{W}$ a $20^{\circ} \mathrm{E}$ ), Oceano Índico $\left(\mathrm{OI}, 20^{\circ} \mathrm{E}\right.$ a $\left.90^{\circ} \mathrm{E}\right)$, Oceano Pacífico Oeste $\left(\mathrm{OPW}, 90^{\circ} \mathrm{E}\right.$ a $\left.160^{\circ} \mathrm{E}\right)$, mar de Ross $\left(\mathrm{MR}, 160^{\circ}\right.$ $\mathrm{E}$ a $130^{\circ} \mathrm{W}$ ) e mares de Bellingshausen-Amundsen (MBA, $130^{\circ} \mathrm{W}$ a $60^{\circ} \mathrm{W}$ ). As anomalias de GM (sem tendência linear e ciclo anual) foram filtradas utilizando a transformada rápida 
de Fourier, no período superior a 365 dias (escala interanual). Para o verão (JFM), foram feitas composições dos campos atmosféricos e de superfície para anos com as cinco maiores anomalias interanuais negativas menos anos com as cinco maiores anomalias interanuais positivas de GM (Tabela 1), conforme a metodologia descrita por Pezza et al. (2008). A significância estatística dos campos de diferença foi obtida através do teste t-Student, ao nível de $10 \%(\alpha=10 \%)$.

Tabela 1 - Anos utilizados para as composições dos campos atmosféricos e de superfície em relação aos extremos de GM para cada setor do Oceano Austral.

\begin{tabular}{|c|c|c|}
\hline & Anomalias Negativas & Anomalias Positivas \\
\hline MW & $1989,90,93,99$ e 02 & $1991,92,95,03$ e 04 \\
\hline OI & $1991,92,97,01$ e 03 & $1989,93,95,00$ e 07 \\
\hline OPW & $1990,93,01,02$ e 06 & $1994,95,96,97$ e 99 \\
\hline MR & $1992,97,04,05$ e 06 & $1989,96,99,01$ e 03 \\
\hline MBA & $1989,92,98,03$ e 07 & $1991,00,02,04$ e 05 \\
\hline
\end{tabular}

\section{RESULTADOS E DISCUSSÃO}

Em extremos de retração de GM nos MBA, MR, OI e OPW, foi observado um leve deslocamento para sul do ramo ascendente da célula da Hadley, apresentando uma intensificação na região equatorial $(\alpha>10 \%)$.

No Pacífico Equatorial, houve um aumento da temperatura da superfície do mar (TSM, $\alpha>10 \%$ ), uma redução da pressão ao nível do mar (PNMM, $\alpha=1 \%$ ) e uma intensificação da convergência em $1000 \mathrm{hPa}(\alpha>10 \%)$ (figuras não apresentadas), o que contribuiu para uma maior atividade convectiva $(\alpha=10 \%)$ e um aumento na precipitação $(\alpha=10 \%)$ (Figuras $1 b$, 1c).

A altura geopotencial em 500 (GEO500) e em 200 (GEO200) hPa foi positiva ( $\alpha=1 \%$ ) (figuras não apresentadas), possivelmente em consequência do aumento da temperatura na média e alta troposfera associado à liberação de calor latente anômala, padrão indicativo de atividade convectiva atípica. Sobre a região Norte do Brasil, associado à retração de GM nos MBA e OI, a divergência em $200 \mathrm{hPa}$ foi negativa $(\alpha>10 \%)$, inibindo a convecção $(\alpha=10 \%)$ e, assim, a precipitação (MBA: $\alpha=10 \%$; OI: $\alpha>10 \%$ ).

Na região Nordeste, em relação ao GM nos MBA e OPW (OI e MR), houve uma menor (maior) precipitação $(\alpha>10 \%$, com exceção do MR, $\alpha=10 \%)$ associada a uma menor (maior) convecção $(\alpha=10 \%)$. Na Região Sul o efeito foi oposto ao Nordeste.

Em extremos de retração de GM no setor do MW houve certo deslocamento para norte do ramo ascendente da célula de Hadley e um enfraquecimento no Equador $(\alpha>10 \%)$ (figuras não apresentadas). No Pacífico Equatorial, houve um resfriamento da TSM ( $\alpha>10 \%)$ e um aumento da divergência em $1000 \mathrm{hPa}(\alpha>10 \%)$ (figuras não apresentadas), inibindo a atividade convectiva $(\alpha=10 \%)$ e a precipitação $(\alpha=10 \%)$ (Figura 1a). Sobre o Norte e Sul do Brasil, o aumento do movimento ascendente $(\alpha>10 \%)$ contribuiu para uma maior convecção $(\alpha=10 \%)$ e precipitação $(\alpha=10 \%)$. O efeito foi contrário na região Nordeste $(\alpha=10 \%)$. Os campos de diferença de PNMM, GEO500 e GEO200 em relação ao GM em todos os setores do Oceano Austral revelam uma estrutura barotrópica equivalente nas latitudes extratropicais. 


\section{ciênciaenatura}

a)

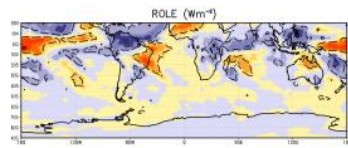

b)

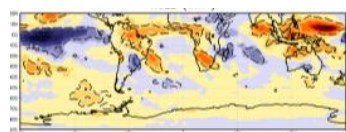

c)

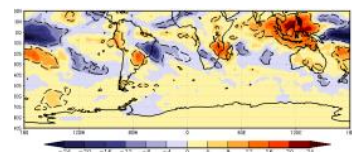

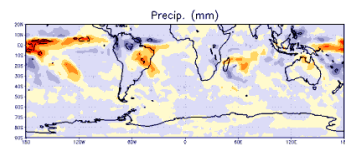
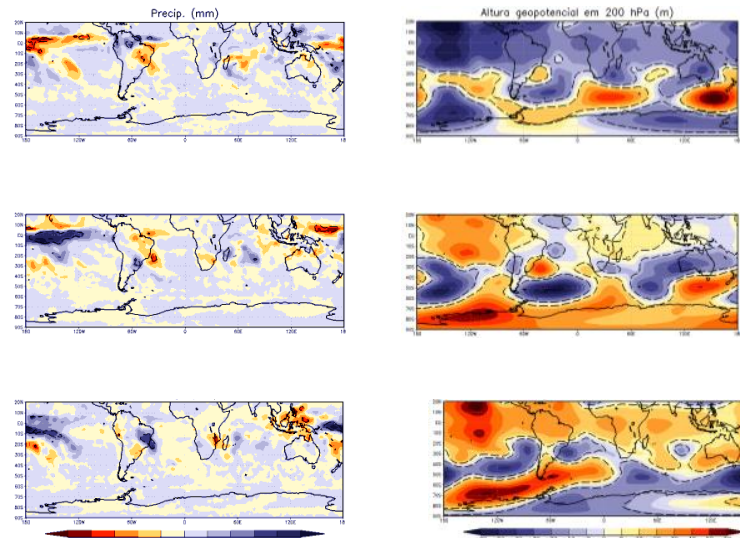

Figura 1: Composições de ROLE ( $\left.\mathrm{Wm}^{-2}\right)$, precipitação $(\mathrm{mm})$ e GEO200 (m) para os setores do (a) MW, (b) MBA e (c) MR. As regiões pontilhadas são significativas ao nível de 10\% (ROLE e precipitação) e $1 \%$ (GEO200).

\section{CONCLUSÕES}

A relação da precipitação sobre a América do Sul com extremos de retração/expansão de GM é distinta nos diferentes setores do Oceano Austral. Com a retração de GM no MR (MBA e MW) houve um aumento (diminuição) de precipitação sobre o Nordeste do Brasil. Sobre a região Sul houve um aumento de precipitação em relação à retração de GM nos MBA. O ramo ascendente da célula de Hadley deslocou-se levemente para sul associado aos extremos de retração de GM na maioria dos setores do Oceano Austral, o que está de acordo com o fato de que a Zona de Convergência Intertropical se desloca em direção ao hemisfério mais quente. Contudo, as composições não apresentaram significância estatística, o que poderia indicar que essa relação não seja tão evidente através das células de circulação meridional, mas sim através de padrões de teleconexão barotrópico equivalente de latitudes extratropicais.

\section{REFERÊNCIAS}

PEZZA, A. B.; DURRANT, T.; SIMMONDS, I.; SMITH, I. Southern Hemisphere synoptic behavior in extreme phases of SAM, ENSO, sea ice extent, and southern Australia rainfall. J Climate, v. 21, p. 5566-5584, 2008. 